\title{
REMOVAL OF METHYLENE BLUE FROM AQUEOUS SOLUTION USING GHASSOUL, A LOW-COST ADSORBENT
}

\author{
ELASS, K. ${ }^{1}{ }^{*}$ - LAACHACH, A. ${ }^{1}-$ ALAOUI, A. ${ }^{1}-$ AZZI, M. ${ }^{2}$ \\ ${ }^{1}$ Laboratory of Analytical and Physical Chemistry, National School of Mineral Industry \\ (ENIM), BP.: 753 Agdal-Rabat, Morocco. \\ (fax: + (212) 37771055) \\ ${ }^{2}$ Laboratory of Electrochemistry and Environment, Faculty of Science \\ Aïn Chock, Casablanca, Morocco \\ *Corresponding author \\ e-mail:khelass@gmail.com \\ (Received $20^{\text {th }}$ April 2009 ; accepted $11^{\text {th }}$ January 2010)
}

\begin{abstract}
The present study examined the use of ghassoul, natural clay available in large quantities under the Atlas Mountains in Morocco, for the removal of the basic dye, methylene blue, from aqueous solutions. The effect of initial dye concentrations, agitation time, $\mathrm{pH}$ and temperature on adsorption capacities of methylene blue was investigated. The initial $\mathrm{pH}$ of the aqueous solution and the change of temperature $\left(25-55^{\circ} \mathrm{C}\right)$ were found to have little effect on the adsorption process. The adsorption was a rapid with $90-99 \%$ of the dye removed within the first 10-20 min. The adsorption kinetics are described successfully using a pseudo-second order rate equation and the rate constant decreases with increasing the initial concentration of MB. Experimental and calculated kinetic data for equilibrium are well expressed by Langmuir isotherm. The equilibrium adsorption capacity of ghassoul was determined with the Langmuir equation as well as the pseudo-second-order rate equation and found to be $>290 \mathrm{mg}$ dye per gram of the adsorbent. The results indicate that ghassoul could be employed as a low cost alternative to commercial activated carbon in wastewater treatment for the removal of colour and dyes.
\end{abstract}

Keywords: natural clay, basic dye, adsorption kinetics

\section{Introduction}

Coloured dye wastewater arises as a direct result of the production of dye and also as a consequence of its use in the textile and others industries (Allen and Koumanova, 2005). Considering both volume-discharged and effluent combustion, the wastewater from the textile industry is rated as the most polluting among all industrial sectors (McKay et al., 1981). Their presence in water, even at very low concentrations, is highly visible and undesirable and may significantly affect photosynthetic activity in aquatic life due to reduced light penetration (Aslihan Gücek et al., 2005). As dyes are toxic to micro-organisms, stable to light irradiation and heat, they cannot be easily removed by conventional wastewater treatment processes due to their complex structure and synthetic origins (Pagga and Taeger, 1994).

In our day various physical-chemical techniques have been studied to assess their applicability for the treatment of this type of industrial discharge. Among these processes may be included coagulation, adsorption, precipitation, flocculation, ozonation (Stephenson and Sheldon, 1996; Churcley, 1998; Nyholm and al., 1992; Ogutveren and Kaparal, 1994; Coro and Laha, 2001; Kang and al., 2000). Of the numerous techniques mentioned, the adsorption process is one of the effective techniques that have been successfully employed for colour removal from wastewater. 
Many adsorbents have been tested to reduce dye concentrations from aqueous solutions. Currently, the most common procedure involves the use of activated carbons (Walker and Weatherley, 1998; Rao and Ashutosh, 1994; Al-Degs et al., 2000) as adsorbents because of their higher adsorption capacities. Despite the prolific use of activated carbon for wastewater treatment, carbon adsorption remains an expensive process, and this fact has recently prompted growing research interest into the production of low-cost alternatives. Various workers have exploited substances such as fly ash (Voudrias et al., 2002; Albanis et al., 2000; Rachakornkij et al., 2004; Mohan et al., 2002), activated carbon prepared from agricultural waste material (Erhan Demirbasa et al., 2004; Kunwar et al., 2003), perlite (Dogan and Alkan, 2003; Dogan et al., 2004), pyrophyllite (Aslıhan Gücek et al., 2005), sepiolite (Alkan et al., 2004; Armagan, 2003), diatomite (Erdem et al., 2005), bentonite (Ozcan et al., 2004; Hu et al., 2006), actived charcoal (Daniela Suteu and Doina Bilba, 2005), chitosan (Ming-Shen Chiou et al., 2003), baggase (Raghuvanshi et al., 2004), alumina (Moreira et al., 1998).

The material used in the present study was prepared with a purified Moroccan clay mineral from mid Moulouya known as a ghassoul or rhassoul. The ghassoul is capable of adsorbing guest cations according to the magnitude of the cation exchange capacity (CEC) (Elmchaouri and Mahboub, 2005; Faust et al., 1959). Considered for its astringent virtues, absorbing and lenitive, ghassoul, clay has a very long history of use in beauty care. Even today it remains a favourite with upscale spas and resorts worldwide. Ghassoul is inexpensive and easily available, this could make it a viable candidate as an economical adsorbent for removing unwanted hazardous components from contaminated water.

The present work aims to study a convenient and economic method for basic dye (Methylene Blue) removal from water by adsorption on an abundantly available adsorbent. Batch studies were carried out involving process parameters such as initial dye concentration, $\mathrm{pH}$, contact time and temperature. Equilibrium and kinetic analysis were conducted to determine the factors controlling the rate of adsorption, the optimization of various parameters in dye recovery and to find out the possibility of using this material as low-cost adsorbent for dye removal.

\section{Materials and methods}

\section{Preparation of adsorbents}

The clay sample used in this investigation was taken from deposits in the careers of Tamdalet in the province of Boulemane, Morocco. The ghassoul sample was treated before using in the experiments as follows: a distilled water suspension of the clay was dispersed for approximately $4 \mathrm{~h}$ and then cleaned several times with de-ionized water. The fine fraction of ghassoul clay was collected by repeated dispersion, sedimentation and siphoning techniques. The solid sample was dried at $105^{\circ} \mathrm{C}$ for $24 \mathrm{~h}$, ground then sieved by $140 \mu \mathrm{m}$ sieve. The sample was analysed for its chemical composition and found to contain $\mathrm{SiO}_{2} 58.16 \%, \mathrm{Al}_{2} \mathrm{O}_{3} 4.48 \%, \mathrm{MgO} 27.44 \%, \mathrm{CaO} 1.88 \%, \mathrm{Fe}_{2} \mathrm{O}_{3} 1.92 \%$, $\mathrm{K}_{2} \mathrm{O} 1.05 \%, \mathrm{Na}_{2} \mathrm{O} 0.17 \%$ and loss on ignition $19.5 \%$. The presence of a significant amount of silicium and a minimum aluminium quantity lead to the supposition that this sample can classified with the silicate family. On another hand it contains a large quantity of magnesium, thus we can consider it as a magnesian smectite. 


\section{Dye and chemicals}

All chemicals used were of analytical reagent grade and supplied by Merck Germany. Stock solutions of the test reagents were made by dissolving Methylene Blue \{3,9-bis dimethyl- aminophenazo thionium chloride\}, in doubly distilled water. The structure of this dye is shown in Fig. 1 .

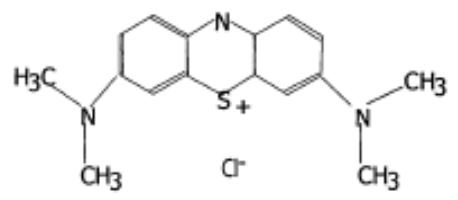

Figure 1. The structure of methylene blue

All colour measurements were made on a Shimadzu 160 UV-visible spectrophotometer in the visible range in absorbance mode. Absorbance values were recorded at the wavelength of maximum absorbance $(\lambda \max =664.5 \mathrm{~nm})$. Absorbance was found to vary linearly with concentration, and dilutions were made when the absorbance exceeded 0.8 .

\section{Adsorption studies}

Adsorption studies were performed by the batch technique to obtain rate and equilibrium data. Various Methylene Blue solutions with different initial concentrations, in the range of $100-600 \mathrm{mg} \mathrm{L}^{-1}$, were prepared by diluting stock dye solution $\left(1 \mathrm{~g} \mathrm{~L}^{-1}\right)$.

Equilibrium experiments, to determine the adsorption capacity of ghassoul, were conducted using $125 \mathrm{~mL}$ centrifuge tubes where $0.2 \mathrm{~g}$ of ghassoul and $100 \mathrm{ml}$ of the above dye solution were added and shaken for $2 \mathrm{~h}$ at $25{ }^{\circ} \mathrm{C}$. Kinetic experiments demonstrate that adsorption equilibrium was reached within 1-2 $\mathrm{h}$.

For the experiments of adsorption kinetics, $1 \mathrm{~g}$ ghassoul sample was added into a litre of dye solution at desired concentration. Under stirring, samples were extracted at selected time intervals (from 10 to $210 \mathrm{~min}$ ) and centrifuged for $10 \mathrm{~min}$ at $3000 \mathrm{rpm}$ and then the concentration of the residual dye $(\mathrm{Ce})$, was determined. The amounts of dyes adsorbed were calculated from the concentrations in solutions before and after adsorption according to the equation:

$$
q e=V \cdot 10^{-3} \times \frac{C_{0}-C e}{m}
$$

where: $q e$ is the equilibrium dye concentration on adsorbent $(\mathrm{mg}$ of dye / $\mathrm{g}$ of sorbent), $C_{0}$ and $C e$ are respectively the initial and the equilibrium concentration of dye in solution $\left(\mathrm{mg} \mathrm{L}^{-1}\right), m$ is the mass of dry adsorbent used $(\mathrm{g})$ and $V$ is the volume of dye solution $(\mathrm{mL})$.

The effect of $\mathrm{pH}$ was observed by studying the adsorption of dye over a $\mathrm{pH}$ range of 3 - 11. The sorption kinetic studies were also carried out at different temperatures, i.e., 25,40 , and $55^{\circ} \mathrm{C}$, to determine the effect of temperature and to evaluate the sorption thermodynamic parameters. The concentration of ghassoul studied was $0.2 \mathrm{~g}$ per 100 $\mathrm{mL}$ of dye solution with the dye concentration of $500 \mathrm{mg} \mathrm{L}^{-1}$. Each experimental point was an average of three independent adsorption tests. 


\section{Results and discussion}

\section{Effect of pH}

The adsorption capacity of Methylene Blue onto ghassoul at various pHs (3, 5, 7, 9 and 11) are shown in Fig. 2. It is seen that the adsorption capacities was affected very slightly by the $\mathrm{pH}$. Since the $\mathrm{pH}$ of freshly prepared dye solution was about 4.5 to 5 , no initial $\mathrm{pH}$ adjustment on the dye solutions was made for subsequent studies.

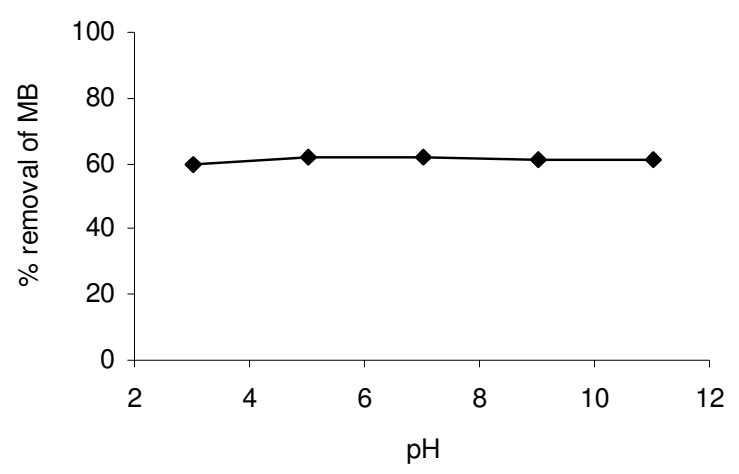

Figure 2. The effect of pH on the adsorption of MB ont ghassoul

\section{Effect of temperature}

The adsorption isotherms at different temperatures $\left(25,40\right.$ and $\left.55^{\circ} \mathrm{C}\right)$ are shown in Fig. 3. The results obtained indicate that the change in temperature in the specified range has almost no effect on the adsorption capacity of Methylene Blue. For this reason, a room temperature of $25^{\circ} \mathrm{C}$ was used throughout this work.

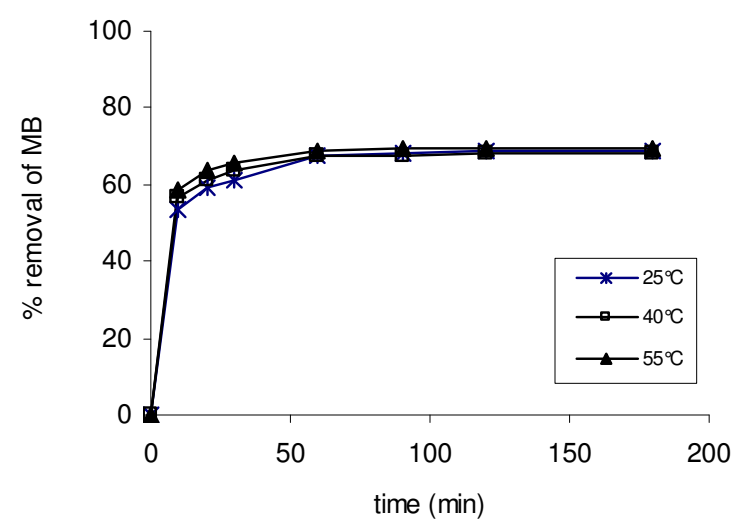

Figure 3. The effect of temperature on the adsorption of MB onto ghassoul 


\section{Adsorption isotherms}

\section{Adsorption equilibrium}

The equilibrium adsorption of Methylene Blue was studied as a function of concentration. The amount of dye adsorbed $q e$, plotted against the equilibrium concentration $\mathrm{Ce}$ for $\mathrm{MB}$, is given in Fig. 4. The equilibrium adsorption of $\mathrm{MB}$ increases with the increase of initial dye concentration, showing the adsorption process to be dependent on the initial concentration. Initially, the adsorption isotherms of dye molecules show a steeply rising part, suggesting a strong affinity of the dye molecules for the surface sites on ghassoul. Then the amount of adsorption reaches a limiting value of around $300 \mathrm{mg} \mathrm{g}^{-1}$. As also seen in Fig. 4, adsorption of Methylene Blue onto ghassoul forms a typical Langmuir-type isotherm, which indicates that dye molecules outcompete water molecules for the sites available on the surface of ghassoul.

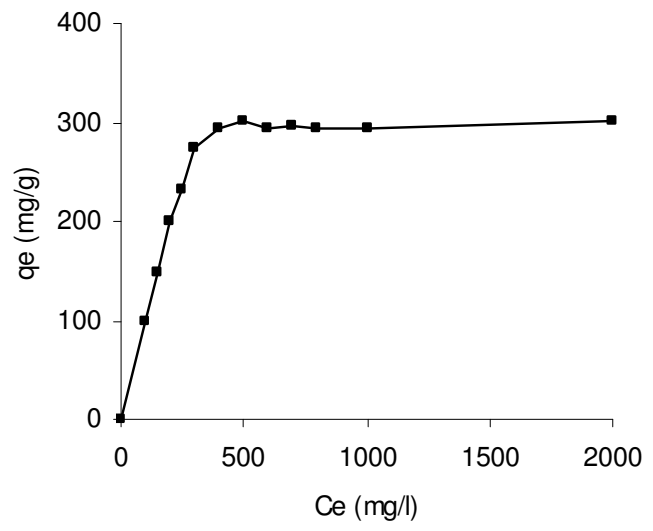

Figure 4. Equilibrium isotherms for MB adsorption onto ghassoul

\section{Isotherm analysis}

Adsorption isotherms are critical in optimizing the use of adsorbents and describe how adsorbate interacts with adsorbent. The analysis of the isotherm data with either theoretical or empirical equations is important to develop an equation which accurately represents the results and which could be used for design purposes (McKay et al., 1985). Several isotherm equations are available. Two of them have been selected in this study: Langmuir and Freundlich isotherms.

The Langmuir isotherm assumes that all the adsorption sites are equivalent and that there is no interaction between adsorbed species (Gupta and Ali, 2001). The Freundlich model assumes a heterogeneous adsorption surface and active sites with different energy (Lagergren, 1998).

The applicability of the Freundlich adsorption isotherm is analyzed by plotting $\log (q e)$ versus $\log (C e)$. Furthermore, the low correlation coefficient $\left(R^{2}=0.7378\right)$ show the poor agreement of the Freundlich isotherm with the experimental data.

The Langmuir isotherm has been widely used to describe single-solute systems. It is based on the assumption that intermolecular forces decrease rapidly with distance and consequently it predicts monolayer coverage of the adsorbate on the outer surface of the 
adsorbent. The isotherm equation further assumes that adsorption takes place at specific homogeneous sites within the adsorbent and there is no significant interaction among adsorbed species. Theoretically, the adsorbent has a finite capacity for the adsorbate. Once a dye molecule occupies a site, no further adsorption can take place at that site. The rate of sorption to the surface should be proportional to a driving force which times an area. The driving force is the concentration in the solution, and the area is the amount of bare surface.

The linear form of the Langmuir equation can be written as follow:

$$
\frac{C e}{q e}=\frac{1}{q m \times K_{L}}+\frac{C e}{q m}
$$

where $q e$ is solid-phase adsorbate concentration at equilibrium $\left(\mathrm{mg} \mathrm{g}^{-1}\right), \mathrm{Ce}$ is aqueous-phase adsorbate concentration at equilibrium $\left(\mathrm{mg} \mathrm{L}^{-1}\right), q m\left(\mathrm{mg} \mathrm{g}^{-1}\right)$ is the maximum amount of dye per unit weight of ghassoul to form a complete monolayer coverage on the surface, $K_{L}$ is the Langmuir constant related to the affinity of binding sites $\left(\mathrm{L} \mathrm{mg}^{-1}\right) . K_{L}$ and $q m$ are computed from the slope and intercept of the straight line of the plot of (Ce/qe) vs. $\mathrm{Ce}$.

Adsorption isotherms were obtained in terms of equations (2) by using experimental adsorption results in this equation. Values for $q m$ and $K_{L}$ are summarised in Table 1. The isotherm data were calculated from the least square method and the related correlation coefficients ( $R^{2}$ values) are given in the same table. As it cab be seen in Table 1, the Langmuir equation represents the adsorption process very well; the $R^{2}$ value was higher than 0.999 , indicating a very good mathematical fit. The fact that the Langmuir isotherm fits the experimental data very well may be due to homogenous distribution of active sites on the ghassoul surface.

Table 1. Values of the constants in Langmuir and Freundlich models

\begin{tabular}{|c|c|c|}
\hline$\underset{\mathbf{m g ~ g}^{-1}}{\mathbf{q m}}$ & $\underset{\mathbf{L} \mathbf{~ m ~ g ~}^{-1}}{\mathbf{K}_{\mathbf{L}}}$ & $\mathbf{R}^{2}$ \\
\hline 294 & 0.59 & 0.9998 \\
\hline
\end{tabular}

The essential characteristic of the Langmuir isotherm may be expressed in terms of the dimensionless separation parameter $R$ (Weber and Chackravorti, 1974), which is indicative of the isotherm shape that predicts whether an adsorption system is 'favourable' or 'unfavourable'. $R$ is defined as:

$$
R=\frac{1}{\left(1+K_{L} \times C_{0}\right)}
$$

where: $K_{L}$ is a Langmuir constant and $C_{0}$ is the initial concentration of dye. 
According to the value of $R$ the isotherm shape may be interpreted as follows:

\begin{tabular}{ll}
\hline Value of $\boldsymbol{R}$ & Type of adsorption \\
\hline$R>1.0$ & unfavourable \\
$R=1.0$ & linear \\
$0<R<1.0$ & favourable \\
$R=0$ & irreversible \\
\hline
\end{tabular}

The initial dye concentration $C_{0}$ used in the adsorption isotherm studies was in the range of 100 to $600 \mathrm{mg} \mathrm{L}^{-1}$ and the corresponding values of parameter $R$ are in the range $0.0164-0.0028$. The fact that all the $R$-values for the adsorption of MB on ghassoul are found to be less than 1 and greater than 0 , shows that the adsorption process is favourable.

$R$ values showed that the adsorption of MB was more favourable for the higher concentration than the lower one, which is due to the effect of the pore diffusion sorption phenomenon.

\section{Adsorption kinetics}

\section{Effect of the initial dye concentration}

The results of methylene blue adsorption with increasing contact time are presented in Fig. 5. On changing the initial concentration of MB solution from 100 to $600 \mathrm{mg} \mathrm{L}^{-1}$, it was found that the MB adsorption increased with increasing contact time. The curves in Fig. 5 show that the adsorption is a very fast process with about $90-99 \%$ of the ultimate adsorption was uptaken by ghassoul within the first 10-20 minutes, indicating high affinity between ghassoul and methylene blue. Then the amount of adsorption reaches a limiting value, beyond which no further adsorption can take place. The necessary time for the equilibrium to be reached was about $90 \mathrm{~min}$. Based on these results, ninety minutes was taken as the equilibrium time in kinetic adsorption experiments.

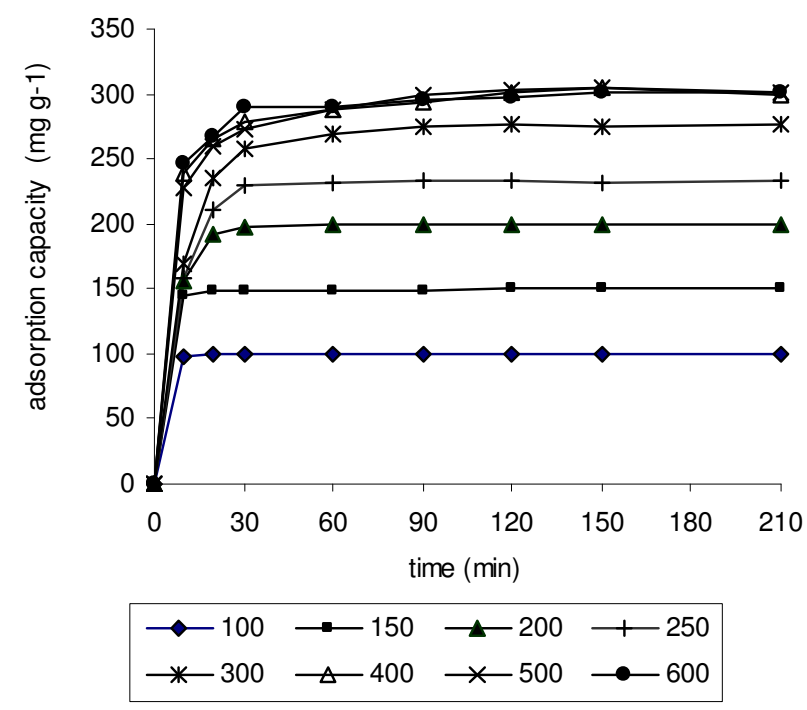

Figure 5. Effect of initial concentration on the adsorption of MB onto ghassoul 


\section{Kinetic studies}

It is important to be able to predict the rate at which contamination is removed from aqueous solutions in order to design an adsorption treatment plant. In order to investigate the mechanism of adsorption and potential rate controlling steps such as mass transfer and chemical reaction, the kinetics of MB sorption onto ghassoul was investigated using two different models: the pseudo-first-order (Lagergren, 1998), and the pseudo second-order (Ho et al., 2000) kinetic models. The conformity between experimental data and the model predicted values was expressed by the correlation coefficients $\left(R^{2}\right.$, values close or equal to 1$)$. A relatively high $R^{2}$ value indicates that the model successfully describes the kinetics of MB adsorption.

The pseudo first-order and the pseudo second-order equations are generally expressed as follows:

$$
\begin{gathered}
\log (q e-q t)=\log q e-\frac{K_{1}}{2.303} \times t \\
\frac{t}{q t}=\frac{1}{K_{2} \times q e^{2}}+\frac{t}{q t}
\end{gathered}
$$

where:

- $q e$ and $q t$ are the adsorption capacity at equilibrium and at time $t$, respectively $\left(\mathrm{mg} \mathrm{g}^{-1}\right)$,

- $K_{1}$ is the rate constant of pseudo first-order adsorption $\left(\mathrm{L} \mathrm{min}^{-1}\right)$,

- $K_{2}$ is the rate constant of pseudo second-order adsorption $\left(\mathrm{g} \mathrm{mg}^{-1} \mathrm{~min}^{-1}\right)$.

The plot of $\log (q e-q t)$ vs. $t$ should give a linear relationship from which $K_{l}$ and $q e$ can be determined from the slope and intercept of the plot, respectively.

The plot of $(t / q t)$ vs. $t$ should give a linear relationship from which $q e$ and $K_{2}$ can be determined from the slope and intercept of the plot, respectively.

Table 2. Comparison of first-Order and second-Order adsorption rate constants, calculated

\begin{tabular}{|c|c|c|c|c|c|c|c|}
\hline \multirow[b]{2}{*}{$\frac{C_{0}}{m g L^{-1}}$} & \multirow[b]{2}{*}{$\underset{\text { mg g }^{-1}}{q_{\text {exp }}}$} & \multicolumn{3}{|c|}{ First-Order Kinetic Model } & \multicolumn{3}{|c|}{ Second-Order Kinetic Model } \\
\hline & & $\begin{array}{c}q e \\
\mathrm{mg} \mathrm{g}^{-1}\end{array}$ & $\begin{array}{c}K_{1} \\
\min ^{-1}\end{array}$ & $R^{2}$ & $\begin{array}{c}q e \\
\mathrm{mg} \mathrm{g}^{-1}\end{array}$ & $\stackrel{K_{2}}{\mathrm{~g} \mathrm{mg}^{-1} \min ^{-1}}$ & $R^{2}$ \\
\hline 100 & 100 & 3.78 & $0.96 \mathrm{E}-2$ & 0.2084 & 100.00 & $66.6 \mathrm{E}-3$ & 1 \\
\hline 150 & 149 & 6.31 & $1.31 \mathrm{E}-2$ & 0.3172 & 149.25 & $22.4 \mathrm{E}-3$ & 1 \\
\hline 200 & 199 & 14.06 & $1.86 \mathrm{E}-2$ & 0.4389 & 200.00 & $6.09 \mathrm{E}-3$ & 0.9999 \\
\hline 250 & 233 & 34.32 & $2.25 \mathrm{E}-2$ & 0.6320 & 238.09 & $2.23 \mathrm{E}-3$ & 0.9996 \\
\hline 300 & 275 & 63.25 & $2.60 \mathrm{E}-2$ & 0,7381 & 277.77 & $1.25 \mathrm{E}-3$ & 0.9994 \\
\hline 400 & 294 & 71.99 & $2.00 \mathrm{E}-2$ & 0.7044 & 303.03 & $1.55 \mathrm{E}-3$ & 0.9996 \\
\hline 500 & 300 & 76.93 & $2.39 \mathrm{E}-2$ & 0.7342 & 303.03 & $1.31 \mathrm{E}-3$ & 0.9996 \\
\hline 600 & 295 & 64.96 & $2.34 \mathrm{E}-2$ & 0.8394 & 303.03 & $1.81 \mathrm{E}-3$ & 0.9998 \\
\hline
\end{tabular}
qe and experimental $q_{\text {exp }}$ values for different initial dye concentrations

Table 2 lists the calculated adsorption constants at different initial dye concentrations by the pseudo first-order and pseudo second-order models. The correlation coefficients, $R^{2}$, of the pseudo first-order model at different initial concentrations $\left(100-600 \mathrm{mg} \mathrm{L}^{-1}\right)$ did not exceed the values of 0.8342 . The calculated qe values are too low compared with experimental $q_{\text {exp }}$ values. This shows that the adsorption of MB by ghassoul did not 
follow the pseudo first-order. The correlation coefficient $R^{2}$ for the pseudo second-order adsorption model has an extremely high value (greater than 0.999), and the calculated qe values also agree very well with the experimental data. These results suggest that the overall rate of the dye adsorption process appears to be controlled by the chemical sorption or chemisorptions process (Aslıhan Gücek et al., 2005; Ho and Mckay, 1998). The similar phenomena have also been observed in the adsorption of MB onto pyrophyllite (Aslihan Gücek et al., 2005) and perlite (Dogan et al., 2004).

According to the pseudo-second order model, the adsorption rate $d q / d t$ is proportional to the second order of $\left(q e-q_{t}\right)$. Since the ghassoul in our experiments had very high equilibrium adsorption capacity $q e$, the adsorption rates became very fast and the equilibrium times were short (Ming-Shen Chiou et al., 2003) Such short equilibrium times coupled with high adsorption capacity indicate a high degree of affinity between the dyes and the ghassoul (Aksu and Tezer, 2000).

\section{Conclusion}

The study of ghassoul as a natural clay adsorbent to remove dye, Methylene Blue, from aqueous solution has been investigated. Ghassoul was shown to be an excellent adsorbent. The results demonstrate that the MB removal is a very fast process, indicating that the adsorption is a surface phenomenon and that the surfaces are readily accessible to the ions in solution. The contact time required for maximum MB adsorption onto ghassoul was found to be nearly $90 \mathrm{~min}$. The data showed that the second-order equation provide the best correlation for the experimental data which indicate the chemical sorption process. The Langmuir model can be used to fit the data and estimate model parameters with adsorption capacity of $290 \mathrm{mg} \mathrm{g}^{-1}$. The adsorption capacity of other adsorbents for MB obtained by some other investigators are presented in Table 3. A comparison of these values with the one obtained in this study showed that ghassoul used in this research exhibited a higher capacity for MB adsorption from aqueous solutions.

Table 3. Adsorption capacity of methylene blue on various adsorbents

\begin{tabular}{lcc}
\hline \multicolumn{1}{c}{ Sorbent } & $\begin{array}{c}\text { Sorption capacity } \\
\left(\mathbf{m g ~ g}^{-\mathbf{1}}\right)\end{array}$ & Reference \\
\hline $\begin{array}{l}\text { Activated carbon } \\
\text { (coconut shell fibbers) }\end{array}$ & 19.59 & 19 \\
\hline $\begin{array}{l}\text { Activated carbon } \\
\text { (olive stones) }\end{array}$ & 303 & 43 \\
\hline Cotton waste & 240 & 45 \\
\hline Date pits & 80.3 & 42 \\
\hline Fly ash & 53.84 & 36 \\
\hline Perlite & $5.6-9.08$ & 18 \\
\hline Perlite & 162.3 & 41 \\
\hline Perlite (EP) & $17.4-31.7$ & 44 \\
\hline Pyrophyllite & 70.42 & 3 \\
\hline Zeolite & 53.1 & 41 \\
\hline
\end{tabular}




\section{REFERENCES}

[1] Aksu, Z., Tezer, S. (2000): Equilibrium and Kinetic Modelling of Biosorption of Remazol Black B by Rhizopus Arrhizus in a Batch System: Effect of Temperature. Process Biochem. 36: 431-439.

[2] Albanis, T.A., Hela, D.G., Sakellrides, T.M., Danis, T.G. (2000): Removal of dyes frm aqueous solutions by adsorption on mixtures of fly ash and soil in batch and column techniques. - Global Nest: the Int. J. 2: 237-244.

[3] Al-Degs, Y., Kharaisheh, M.A.M., Allen, S.J., Ahmad, M.N. (2000): Effect of Carbon Surface Chemistry on the Removal of Reactive Dyes from Textile Effluent. - Water Res. 34: 927-935.

[4] Alkan, M., Demirbaş, O., Doğan, M. (2004): Removal of acid yellow 49 from aqueous solution by adsorption. - Fresenius Environmental Bulletin 13: 1112-1121.

[5] Allen, S.J., Koumanova, B. (2005): Decolourisation of water/wastewater using adsorption (review). - Journal of the University of Chemical Technology and Metallurgy 40: 175192.

[6] Armagan, B. (2003): Factors affecting the performances of sepiolite and zeolite for the treatment of textile wastewater. - J. Environ. Sci. Health A Tox. Hazard. Subst. Environ. Eng. 38: 883-896.

[7] Banat, F., Al-Asheh, S., Al-Makhadmeh, L. (2003): Evaluation of the use of raw and activated date pits as potential adsorbents for dye containing waters. - Process Biochem. 39: 193-202.

[8] Churcley, J. (1998): Ozone for dye waste colour removal. - Ozone-science and Engineering. 20: 111-120.

[9] Coro, E., Laha, S. (2001): Color removal in ground water through enhanced softening process. - Water Res. 35: 1851-1854.

[10] Demirbasa, E., Kobyab, M., Senturkb, E., Ozkana, T. (2004): Adsorption kinetics for the removal of chromium (VI) from aqueous solutions on the activated carbons prepared from agricultural wastes. - Water SA. 30: 533-540.

[11] Dinesh Mohan, Kunwar P. Singh, Gurdeep Singh, Kundman Kumar, (2002): Removal of dyes from wastewater using flyash, a low-cost adsorbent. - Ind. Eng. Chem. Res. 41: 3688-3695.

[12] Dogan, M., Alkan, M. (2003): Adsorption kinetics of methyl violet onto perlite. Chemosphere 50: 517-528.

[13] Dogan, M., Alkan, M. (2003): Removal of methyl violet from aqueous solution by perlite. - J. Coll. Interf. Sci. 267: 32-41.

[14] Dogan, M., Alkan, M., Onager, Y. (1998): Adsorption of methylene blue from aqueous solution onto perlite. - Water Air Soil Pollut. 120: 229-248.

[15] Dogan, M., Alkan, M., Onager, Y. (2000): Adsorption of Methylene Blue from Aqueous Solution onto Perlite. - Water, Air, Soil Pollut. 120: 229-248.

[16] Dogan, M., Alkan, M., Türkyilmaz, A., Özdemir, Y. (2004): Kinetics and mechanism of removal of methylene blue by adsorption onto perlite. - J.Hazard. Mat. B109: 141-148.

[17] Elmchaouri, A., Mahboub, R. (2005): Effect of preadsorption f organic amine on AlPILCs structures. - Colloids and Surfaces A: Physicochem. Eng. Aspects 259: 135-141.

[18] Erdem, E., Colgecen, G., Donat, R. (2005): The removal of textile dyes by diatomite earth. - J. Coll. Inter. Sci. 282: 314-319.

[19] Faust, G.T., Hathaway J.C., Millot, G. (1959): A restudy of stevensite and allied minerals. - Am. Miner. 44: 342-370.

[20] Gücek, A., Sener, S., Bilgen, S., Mazmancı, M.A. (2005): Adsorption and kinetic studies of cationic and anionic dyes on pyrophyllite from aqueous solutions. - J. Coll. Interf. Sci. 286: 53-60.

[21] Gupta, V.K., Ali, I. (2001): Removal of DDD and DDE from wastewater using bagasse fly ash, a sugar industry waste. - Water Research 35: 33- 40. 
[22] Ho, Y.S., Mckay, G. (1998): Comparison of chemisorption kinetic models applied to pollutant removal on various sorbents. - Trans IChemE. 76B: 332-340.

[23] Ho, Y.S., Mckay, G., Wase, D.A.J., Foster, C.F. (2000): Study of the sorption of divalent metal ions on to peat. - Adsorp. Sci. Technol. 18: 639-650.

[24] Hu, Q.H., Qiao, S.Z., Haghseresht, F., Wilson, M.A., Lu, G.Q. (2006): Adsorption Study for Removal of Basic Red Dye Using Bentonite. - Ind. Eng. Chem. Res. 45: 733-738.

[25] Kang, S., Liao, C., Po, S. (2000): Decolorization of textile wastewater by photo-fenton oxidation technology. - Chemosphere 41: 1287-1294.

[26] Kunwar P. Singh, Dinesh Mohan, Sarita Sinha, Tondon, G. S., Devlina Gosh, (2003): Color removal from wastewater using low-cost adsorbed carbon derived from agricultural waste material. - Ind. Eng. Chem. Res. 42: 1965-1976.

[27] Lagergren, S. (1998): About the theory of so-called adsorption of soluble substances. Kungliga Svenska Vetenskapsakademiens. Handlingar 24: 1-39.

[28] McKay, G., Otterburn, M.S., Aga, A.J. (1985): Fuller's earth and fired clay as adsorbents for dye stuffs equilibrium and rate studies. - Water, Air and Soil Pollution 24: 307-312.

[29] McKay, G., Otterburn, M.S., Sweeney, A.G. (1981): Surface Mass Transfer Processes During Colour Removal from Effluent Using Silica. - Water Res. 115: 327-331.

[30] Mckay, G., Ramprasad, G., Pratapamowli, P. (1986): Equilibrium studies for the adsorption of dyestuffs from aqueous solution by low-cost materials. - Water Air Soil Pollut. 29: 273-283.

[31] Ming-Shen Chiou, Pang-Yen Ho, Hsing-Ya Li (2003): Adsorption Behavior of Dye AAVN and RB4 in Acid Solutions on Chemically Cross-Linked Chitosan Beads. - J. Chin. Inst. Chem. Engrs. 34: 625-634.

[32] Moreira, R.F.P.M., Peruch, M.G., Kuhnen, N. C. (1998): Adsorption of textile dyes on alumina. Equilibrium studies and contact time effects. - Braz. J. Chem. Eng. 15: $\mathrm{n}^{\circ} 1$

[33] Najar-Souissi, S., Ouederni, A., Ratel, A. (2005): Adsorption of dyes onto activated carbon prepared from olive stones. - J Environ. Sci. (China) 17: 998-1003.

[34] Nyholm, N., Jacobsen, B.N., Pedersen, B.M., Poulsen, O., Damborg, A., Schultz, B. (1992): Removal of organic micropollutants at ppb levels in laboratory activated sludge under various operating conditions. - Water Resources 26: 339-353.

[35] Ogutveren, U., Kaparal, S. (1994): Color removal from textile effluents by electrochemical destruction. - J. Environ. Sci. Health A 29: 1-16.

[36] Ozcan, A S., Erdem, B., Ozcan, A. (2004): Adsorption of Acid Blue 193 from aqueous solutions onto Na-bentonite and DTMA-bentonite. - J Coll. Inter. Sci. 280: 44-54.

[37] Pagga, U.M., Taeger, K. (1994): Development of a method for adsorption of dyestuffs on activated sludge. - Water Resources 28: 1051-1057.

[38] Rachakornkij, M., Ruangchuaya, S., Teachakulwiroj, S. (2004): Removal of reactive dyes from aqueous solution using bagasse fly ash. - Songklanakarin J. Sci. Technol. 26: 13-24.

[39] Raghuvanshi, S.P., Singhi, R., Kaushik, C.P. (2004): Removal of reactive dyes from aqueous solution using bagasse fly ash. - Songklanakarin J. Sci. Technol. 2: 35-43.

[40] Rao, K., Ashutosh, K.K. (1994): Color Removal from Dyestuff Industry Effluent Using Activated Carbon. - Indian J. Chem. Tech. 1: 13-19.

[41] Stephenson, R.J., Sheldon, J.B. (1996): Coagulation and Precipitation of a Mechanical Pulping Effluent: 1. Removal of Carbon and Turbidity. - Water Res. 30: 781-792.

[42] Suteu, D, Bilba, D. (2005): Equilibrium and Kinetic Study of Reactive Dye Brilliant Red HE-3B Adsorption by Activated Charcoal. - Acta Chim. Slov. 52: 73-79.

[43] Voudrias, E., Fytianos, K., Bozani, E. (2002): Sorption-desorption isotherms of dyes from aqueous solutions and wastewaters with different sorbent materials. - Global Nest: the Int. J. 4: 75-83.

[44] Walker, G.M., Weatherley, L.R. (1998): Fixed Bed Adsorption of Acid Dyes onto Activated Carbon. - Environ. Pollut. 99: 133-136.

[45] Weber, T.W., Chackravorti, R.K. (1974): Pore and solid diffusion models for fixed bed adsorbers. - Amer. Inst. Chem. Eng. J. 20: 228-238. 